\title{
Aortic Arch Malformations and Ventricular Septal Defect in Mice Deficient in Endothelin-1
}

\author{
Yukiko Kurihara, * Hiroki Kurihara, * Hideaki Oda, ${ }^{\ddagger}$ Koji Maemura, * Ryozo Nagai, * Takatoshi Ishikawa, \\ and Yoshio Yazaki* \\ ${ }^{*}$ The Third Department of Internal Medicine and ${ }^{\ddagger}$ Department of Pathology, Faculty of Medicine, University of Tokyo, \\ Tokyo 113, Japan
}

\begin{abstract}
Endothelin-1 (ET-1) is a 21-amino acid peptide with various biological activities including vasoconstriction and cell proliferation. To clarify the physiological and pathophysiological role of ET-1, we disrupted the mouse Edn1 locus encoding ET-1 by gene targeting and demonstrated that ET1 is essential to the normal development of pharyngeal archderived tissues and organs. In this study, we focused on the phenotypic manifestations of $E d n 1^{-1-}$ homozygous mice in the cardiovascular system. Edn1 $1^{-1-}$ homozygotes display cardiovascular malformations including interrupted aortic $\operatorname{arch}(2.3 \%)$, tubular hypoplasia of the aortic arch $(4.6 \%)$, aberrant right subclavian artery $(12.9 \%)$, and ventricular septal defect with abnormalities of the outflow tract $(48.4 \%)$. The frequency and extent of these abnormalities are increased by treatment with neutralizing monoclonal antibodies or a selective $\mathbf{E T}_{\mathrm{A}}$ receptor antagonist BQ123. At an earlier embryonic stage, formation of pharyngeal arch arteries and endocardial cushion is disturbed in $E d n 1^{-1-}$ homozygotes. In situ hybridization confirmed ET-1 expression in the endothelium of the arch arteries and cardiac outflow tract and the endocardial cushion as well as in the epithelium of the pharyngeal arches. Thus, ET-1 is involved in the normal development of the heart and great vessels, and circulating ET-1 and/or other ET isoforms may cause a functional redundancy, at least partly, through the $\mathbf{E T}_{\mathbf{A}}$ receptor. (J. Clin. Invest. 1995. 96:293-300.) Key words: endothelin-1 - gene targeting - cardiovascular development - neural crest • congenital heart disease
\end{abstract}

\section{Introduction}

Endothelin-1 (ET-1) ${ }^{1}$ was first identified as a vasoconstrictor peptide in the supernatant of cultured vascular endothelial cells

Address correspondence to Hiroki Kurihara, The Third Department of Internal Medicine, Faculty of Medicine, University of Tokyo, 7-3-1 Hongo, Bunkyo-ku, Tokyo 113, Japan. Phone: 3-3815-5411x3100; FAX: 3-3815-2087.

Received for publication 28 November 1994 and accepted in revised form 28 February 1995.

1. Abbreviations used in this paper: d.p.c., days postcoitum; ET, endothelin.

J. Clin. Invest.

(c) The American Society for Clinical Investigation, Inc.

0021-9738/95/07/0293/08 \$2.00

Volume 96, July 1995, 293-300
(1). Three isopeptides (ET-1, -2 , and -3 ) encoded by different gene loci constitute a gene family (2) and act on two distinct $\mathrm{G}$ protein-coupled receptors $\left(\mathrm{ET}_{\mathrm{A}}\right.$ and $\left.\mathrm{ET}_{\mathrm{B}}\right)$ with different affinities $(3,4)$. In addition to vasoconstrictive effects on vascular smooth muscle cells, ET-1 has a diverse set of biological activities such as proliferative effects on various cells, stimulation of hormone release, and modulation of central nervous activity (5). ET-1 also acts on endothelial cells in an autocrine manner and stimulates nitric oxide and prostacyclin release (6). These effects of ET-1 suggest that ET-1 may participate in the regulation of cardiovascular homeostasis and the pathogenesis of cardiovascular disease such as hypertension, vasospasm, and atherosclerosis (7-9). However, there has been little consensus about the physiological and pathophysiological importance of ET-1. Recently, we disrupted the mouse Ednl locus encoding ET-1 by gene targeting (10). The resultant mice homozygous for ET-1 null mutation represent morphological abnormalities of the pharyngeal arch-derived craniofacial tissues and organs, indicating that ET-1 is essential to normal embryonic development.

In mammalian craniofacial morphogenesis, mesenchyme constituting the pharyngeal arches stems mainly from neural crest cells. Cranial neural crest cells migrate to the pharyngeal arch region and differentiate into ectomesenchymal cells. Neural crest-derived ectomesenchymal cells interact with surface ectoderm, resulting in further differentiation into various tissues such as cartilage and dentine of the teeth $(11,12)$. In situ hybridization detected ET-1 gene expression in the epithelium of pharyngeal arches (10), suggesting that ET-1 may be involved in this epithelial-mesenchymal interaction. Neural crest cells are also required for normal cardiovascular development (13-15). Ectomesenchymal cells derived from cardiac neural crest migrate to pharyngeal arches 3,4 , and 6 and contribute to the aortic arch development and aorticopulmonary septation. Thus, we speculated that ET-1 may participate not only in craniofacial development but also in cardiovascular development. In this study, we focused on the phenotypic manifestations of $E d n 1^{-1-}$ homozygous mice in the cardiovascular system to examine the possibility that ET-1 may also contribute to embryonic cardiovascular development.

\section{Methods}

Mice. ET-1 knockout mice were established by gene targeting (10). The animals were maintained on a light-dark cycle with light from 9:00 to $21: 00$ at $25^{\circ} \mathrm{C}$. Mice were fed with a normal diet and water ad libitum. Mice heterozygous for $E d n 1^{-}$mutant allele with the genetic background of the $129 \mathrm{~Sv} / \mathrm{J} \times \mathrm{ICR}$ hybrid were mated. In some $E d n I^{+/-}$ heterozygous pregnant females intercrossed with $E d n 1^{+/-}$heterozygous males, osmotic minipumps (Alzet model 1007D; Alza Corp., Palo Alto, CA) containing anti-ET-1 monoclonal antibodies HPE37B11 (16) 
Table I. Cardiovascular Abnormalities in Edn ${ }^{-1-}$ Homozygous Mice

\begin{tabular}{lccc}
\hline & $\begin{array}{c}\text { Untreated } \\
(\%)\end{array}$ & $\begin{array}{c}\text { mAb-treated } \\
(\%)\end{array}$ & $\begin{array}{c}\text { BQ123-treated } \\
(\%)\end{array}$ \\
\hline Abnormalities of the great vessels & & & \\
Tubular hypoplasia of the aorta & $2 / 43(4.6)$ & $11 / 55(20.0)^{*}$ & $7 / 34(20.6)^{*}$ \\
Interruption of the aorta & $1 / 43(2.3)$ & $8 / 55(14.5)^{*}$ & $8 / 34(23.5)^{\ddagger}$ \\
Absent right subclavian artery & $4 / 31(12.9)$ & $11 / 43(25.6)$ & $13 / 21(61.9)^{\ddagger}$ \\
Ventricular septal defect & $15 / 31(48.4)$ & $29 / 35(82.9)^{\ddagger}$ & $17 / 19(89.5)^{\ddagger}$
\end{tabular}

${ }^{*} P<0.05,{ }^{\ddagger} P<0.01$ versus the control untreated group.

(0.11 mg/d per mouse) or $\mathrm{ET}_{\mathrm{A}}$ antagonist BQ123 (17) $(0.96 \mathrm{mg} / \mathrm{d}$ per mouse) were subcutaneously implanted at $5.5-8.5 \mathrm{~d}$ postcoitum (d.p.c.) to achieve continuous infusion for $7 \mathrm{~d}$. HPE37B 11 ( IgG $_{1}$ subtype $)$ recognized the $\mathrm{COOH}$-terminal region of ET-1, crossreacted with ET-2 and ET-3, and neutralized the pressor effect of intravenously administered ET-1 ( $1 \mathrm{nmol} / \mathrm{kg}$ of body wt) (data not shown). Continuous infusions of saline or monoclonal antibodies of the same $\mathrm{IgG}_{1}$ subtype, which recognize rat intercellular adhesion molecule but do not recognize mouse intercellular adhesion molecule, served as control experiments. The dose of BQ123 was sufficient for antagonizing the effect of ET-1 through $\mathrm{ET}_{\mathrm{A}}$ receptors (18). Pregnant mice were killed by cervical dislocation and the fetuses were dissected from uterine decidua. $E d n 1^{-1-}$ homozygous fetuses were identified by their characteristic craniofacial abnormalities and genotypes were confirmed by Southern analysis of tail genomic DNA samples. The heart and great vessels of $E d n 1^{-1-}$ homozygous fetuses were observed by stereoscopy. For histological examinations, hearts were excised, fixed in $4 \%$ paraformaldehyde, and embedded in paraffin. They were serially sectioned into 8$\mu \mathrm{m}$ sections and stained with hematoxylin and eosin. The terminology and diagnosis of the anomalies were principally based on the established descriptions (19).

Whole mount in situ hybridization. A 1.0-kb fragment of the mouse ET-1 cDNA (Maemura, K., manuscript submitted for publication) was
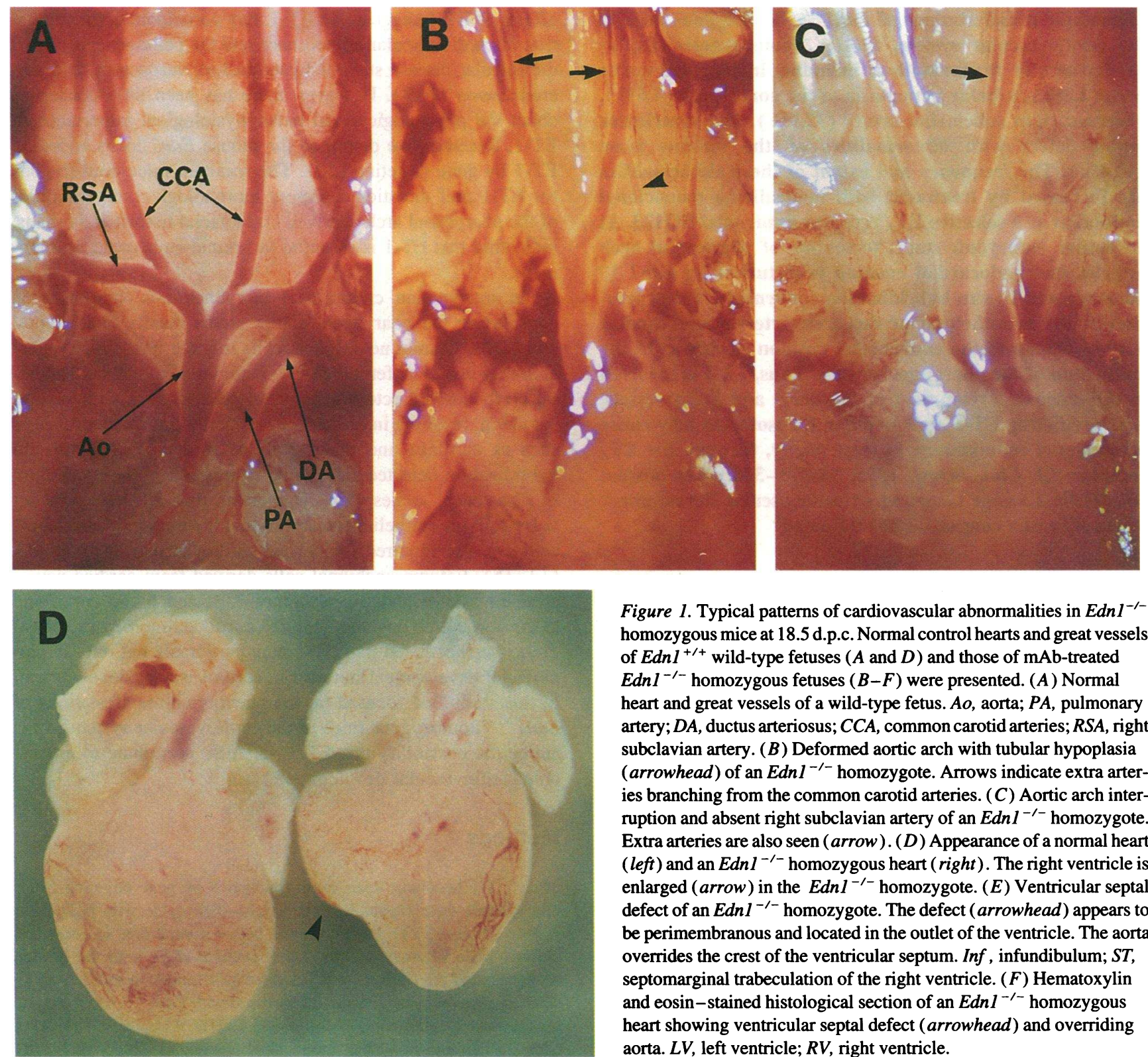

Figure 1. Typical patterns of cardiovascular abnormalities in $E d n 1^{-1-}$ homozygous mice at 18.5 d.p.c. Normal control hearts and great vessels of $E d n I^{+/+}$wild-type fetuses $(A$ and $D)$ and those of mAb-treated $E d n 1^{-1-}$ homozygous fetuses $(B-F)$ were presented. $(A)$ Normal heart and great vessels of a wild-type fetus. $A o$, aorta; $P A$, pulmonary artery; $D A$, ductus arteriosus; $C C A$, common carotid arteries; $R S A$, right subclavian artery. $(B)$ Deformed aortic arch with tubular hypoplasia (arrowhead) of an Edn1 ${ }^{-/-}$homozygote. Arrows indicate extra arteries branching from the common carotid arteries. $(C)$ Aortic arch interruption and absent right subclavian artery of an $E d n 1^{-1-}$ homozygote. Extra arteries are also seen (arrow). (D) Appearance of a normal heart (left) and an $E d n 1^{-1-}$ homozygous heart (right). The right ventricle is enlarged (arrow) in the $E d n 1^{-1-}$ homozygote. (E) Ventricular septal defect of an $E d n 1^{-1-}$ homozygote. The defect (arrowhead) appears to be perimembranous and located in the outlet of the ventricle. The aorta overrides the crest of the ventricular septum. Inf, infundibulum; $S T$, septomarginal trabeculation of the right ventricle. $(F)$ Hematoxylin and eosin-stained histological section of an $E d n 1^{-1-}$ homozygous heart showing ventricular septal defect (arrowhead) and overriding aorta. $L V$, left ventricle; $R V$, right ventricle. 

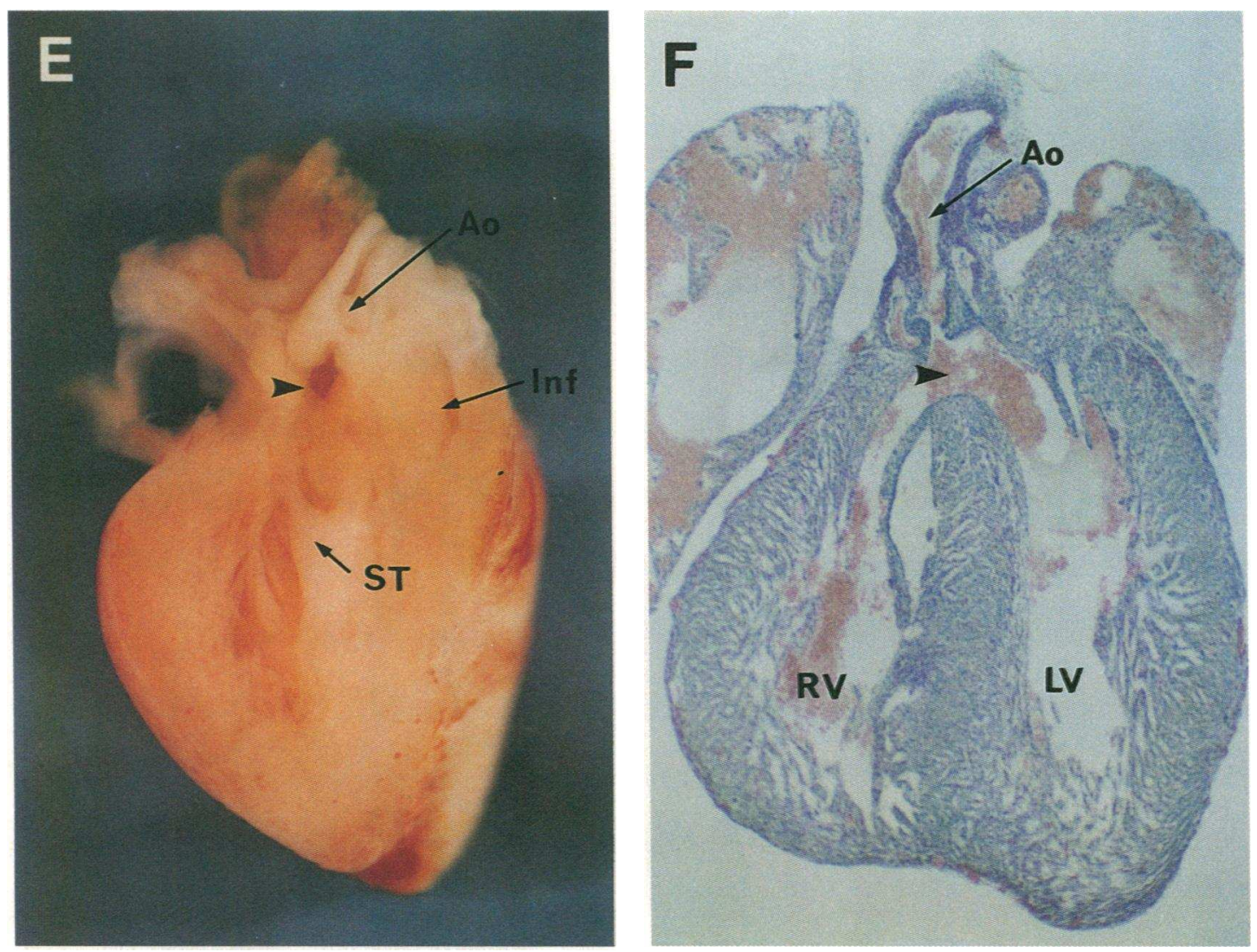

Figure 1 (Continued)

subcloned in pBluescriptSK ${ }^{+}$and nonradioactive antisense RNA probes were synthesized with digoxygenin-11-UTP (Boehringer Mannheim Corp., Indianapolis, IN). Whole-mount fixation and in situ hybridization were performed as described (20). Hybridized embryos or hearts were washed at high stringency, incubated with alkaline phosphatase-conjugated anti-digoxygenin antibody, and stained with nitro blue tetrazolium and 5-bromo-4-chloro-3-indoyl phosphate. For sections, hybridized embryos were fixed in $4 \%$ paraformaldehyde, embedded in paraffin, serially sectioned, and faintly stained with eosin.

Statistical analysis. Statistical comparison used $\chi^{2}$ test. A value of $P<0.05$ was considered significant.

\section{Results}

Cardiovascular phenotype of Edn1 $1^{-1-}$ homozygous mice. Table I summarizes the cardiovascular malformations of $E d n 1^{-1-}$ homozygous fetuses at 18.5 d.p.c. Some $E d n 1^{-1-}$ homozygotes displayed tubular hypoplasia of the aortic arch (Fig. $1 B$ ), interruption of the aorta distal to the left common carotid artery (Fig. $1 \mathrm{C}$ ), and/or absence of the proximal segment of the right subclavian artery (Fig. $1 C$ ). Even $E d n 1^{-1-}$ homozygotes without hypoplasia or interruption showed aortic arch deformity in which the arch seemed to be pulled upward in a manner similar to that shown in Fig. $1 B$. In most $E d n 1^{-/-}$homozygotes, additional small arteries branched from the common carotid arteries (Fig. 1, B and C). Furthermore, many $E d n 1^{-1-}$ homozygotes also showed tiny ventricular septal defect, which was increased in size and well characterized by using monoclonal antibodies or a receptor antagonist (described below).
Effects of anti-ET-1 monoclonal antibodies and ET antagonist on the cardiovascular phenotype. Because these cardiovascular malformations appeared in $E d n 1^{-1-}$ homozygotes with incomplete penetration, we hypothesized that ET-1 function may be partially compensated by maternally derived circulating ET-1 or other ET isoforms, ET-2 and ET-3. To test this hypothesis, we implanted osmotic minipumps containing neutralizing monoclonal antibodies specific for ETs or an $\mathrm{ET}_{\mathrm{A}}$ receptorselective antagonist, $\mathrm{BQ} 123$, in pregnant $E d n 1^{+/-}$heterozygotes and examined the phenotype of the offspring. Continuous administration of monoclonal antibodies or BQ123 resulted in increased occurrence of aortic arch malformations in $E d n 1^{-1-}$ homozygotes (Table I). Ventricular septal defect was encountered more frequently and the defect size tended to be larger than untreated $E d n 1^{-1-}$ homozygotes (Table I). The ventricular septal defect is perimembranous and located beneath the outflow tract supporting the aortic valve (Fig. $1, E$ and $F$ ). The aorta frequently overrode the crest of the ventricular septum or arose mainly from the right ventricle (Fig. 1, E and $F$ ). The right ventricles were typically dilated, which indicates volume overload probably due to left-to-right shunt (Fig. $1 D$ ). Continuous infusion of saline or control monoclonal antibodies did not increase the frequency or extent of the cardiovascular abnormalities of $E d n 1^{-1-}$ mice (data not shown). These results suggest that circulating ET-1 and/or other ET isoforms may compensate the role of endogenous ET-1 in cardiovascular development and this functional redundancy may be mediated by, at least in part, $\mathrm{ET}_{\mathrm{A}}$ receptor. Neither cardiovascular nor craniofacial abnormal- 

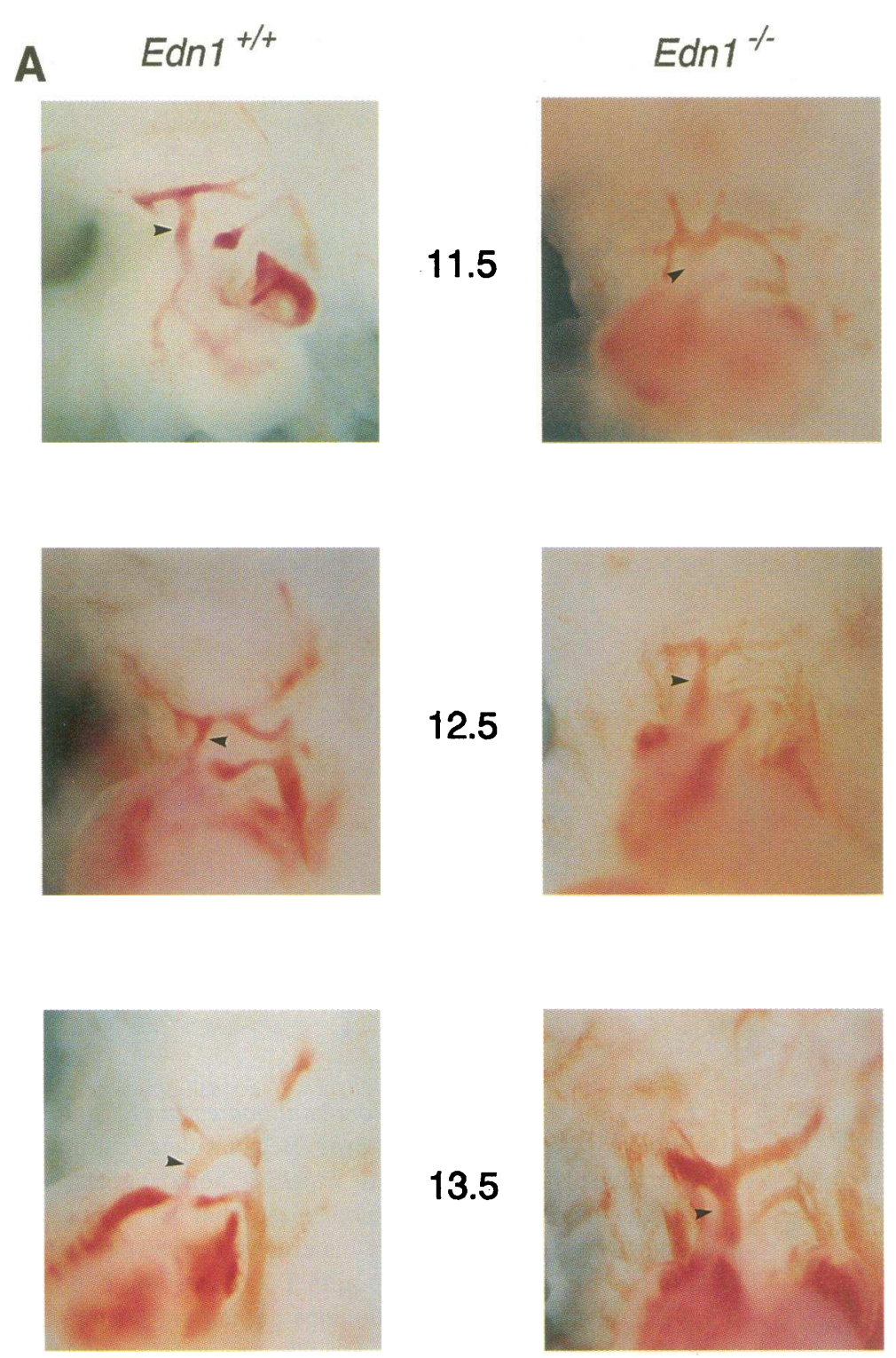

B

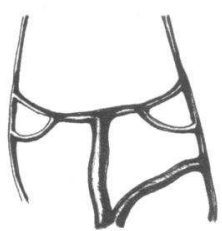

11.5
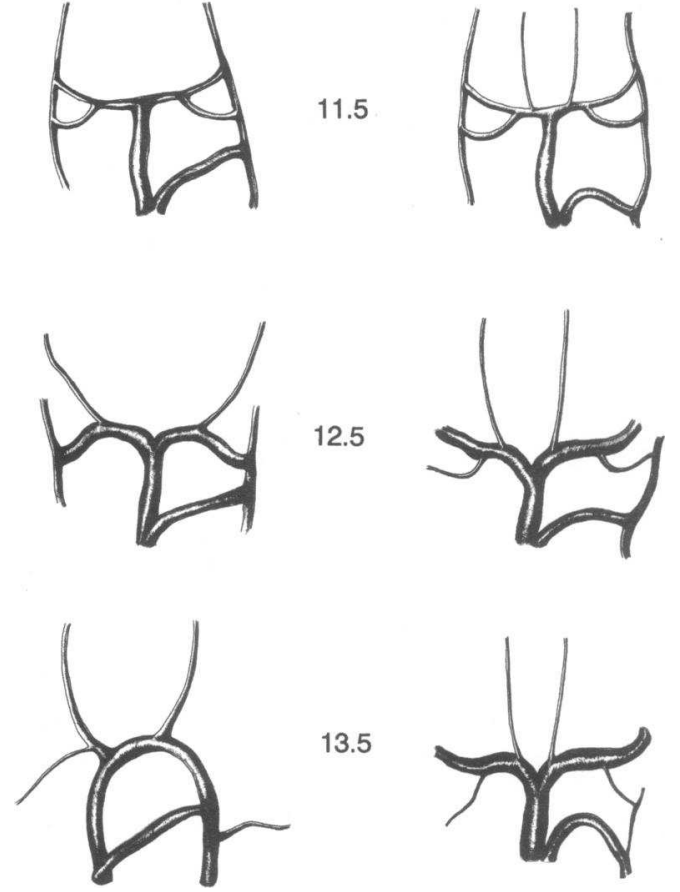

Figure 2. Development of the cardiovascular system in $E d n 1^{+/+}$wild-type and $E d n 1^{-/-}$homozygous mice. ( $A$ and $B)$ Photographs and schematic drawings of the arch arteries at $11.5,12.5$, and 13.5 d.p.c. in $E d n 1^{+/+}$wild-type and $E d n 1^{-/-}$homozygous mice. The first or second pharyngeal arch artery persists and the fourth arch artery is poorly developed in $\mathrm{EdnI}^{-1-}$ homozygotes. Arrowheads indicate the ventral aorta. $(C-E)$ Histological sections of the heart at 13.5 d.p.c. in an $E d n 1^{+/+}$wild-type mouse $(C)$, an mAbtreated $E d n 1^{-1-}$ homozygote $(D)$, and an $E d n 1^{-/-}$homozygote treated with BQ123 $(E)$. Development of the endocardial cushion $(E C)$ is retarded and the ventricular septum (arrow) is defective in $E d n 1^{-/-}$homozygotes. In a BQ123treated $E d n 1^{-1-}$ homozygote, hypoplasia of the compact zone of the ventricular wall (arrowhead) is also displayed. ities were found in $\mathrm{Edn1^{+/- }}$ heterozygous or $\mathrm{EdnI}^{+/+}$wild-type littermates in any condition, suggesting that neither neutralizing antibodies nor BQ123 at the doses used is sufficient to abolish the role of endogenous ET-1 in embryogenesis.

Developmental patterns of the pharyngeal arch arteries. To clarify the genesis of these cardiovascular abnormalities in $E d n 1^{-1-}$ homozygotes, we compared the developmental patterns of the pharyngeal arch arteries and heart at the stage of organogenesis. In normal embryos, the first and second arch arteries disappear before 11 d.p.c. and the left fourth arch artery well develops to generate the isthmus of the aortic arch together with the dorsal aorta. The third arch arteries and the right fourth artery give rise to the common carotid arteries and the proximal region of the right subclavian artery, respectively (see reference 21 and Fig. 2, $A$ and $B$ ). In $E d n 1^{-1-}$ homozygous embryos, the first or second arch artery persisted, possibly corresponding to the extra arteries branching from the carotid arteries at 18.5 d.p.c., and both of the fourth arch arteries were diminished (Fig.
$2, A$ and $B$ ). Instead, a communication between the left third arch artery and dorsal aorta seemed to form the deformed aorta. The occurrence of aortic tubular hypoplasia or interruption seemed to be dependent on the development of the dorsal aorta between the third arch artery and ductus arteriosus (the sixth arch artery ). Thus, alterations in the pattern of arch artery development lead to the aortic arch abnormalities in $E d n 1^{-1-}$ homozygotes. In the heart of $E d n 1^{-1-}$ homozygotes, endocardial cushion at the site of septation was poorly developed without fusing to the muscular septum (Fig. 2, $C$ and $D$ ). In some of BQ123-treated embryos, cell proliferation in the compact zone of the ventricular wall is poor (Fig. $2 E$ ).

ET-1 gene expression in the embryonic cardiovascular system. The role of ET-1 in cardiovascular development was also studied using in situ hybridization. High ET-1 gene expression was detected in the endocardium of the outflow tract of the heart, the endothelium of the arch arteries, and dorsal aorta in addition to the epithelium of the pharyngeal arches in 10.0 d.p.c. 


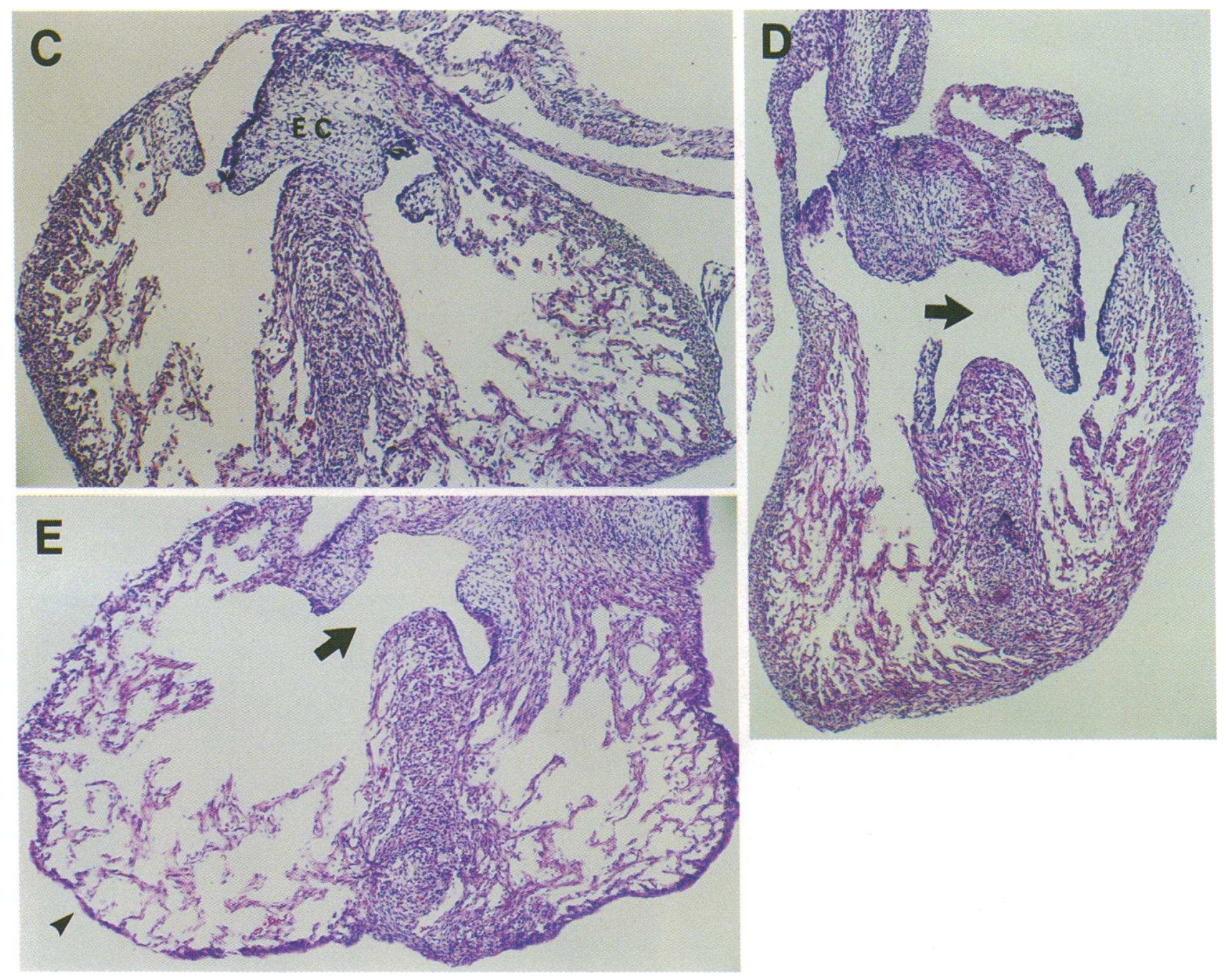

Figure 2 (Continued)

embryos (Fig. 3, $A$ and $B$ ). In the heart of 11.5 d.p.c. embryos, ET-1 signal was apparent in the conotruncal region in a spiral pattern (Fig. $3 \mathrm{C}$ ). The section of the specimen showed that ET-1 expression is predominant in the endocardium as well as the mesenchyme of the endocardial cushion at this stage (Fig. $3 D$ ). These results support the notion that ET-1 is involved in the development of the heart and great vessels.

\section{Discussion}

In this study, we have demonstrated that $E d n 1^{-1-}$ homozygous mice develop cardiovascular malformations involving the heart and great vessels with incomplete penetration. Treatment with neutralizing monoclonal antibodies specific for $\mathrm{ET}$ or $\mathrm{ET}_{\mathrm{A}}$ receptor antagonist BQ123 significantly increased the frequency and extent of these cardiovascular abnormalities. The development of the pharyngeal arch arteries and endocardial cushion is affected in Edn1 ${ }^{-/-}$homozygotes. Furthermore, ET-1 gene is expressed in the endothelium of the arch arteries and cardiac outflow tract and the endocardial cushion as well as in the epithelium of the pharyngeal arches at the stage of early organo- genesis. These results indicate a novel role of ET-1 in cardiovascular development through, at least partly, $\mathrm{ET}_{\mathrm{A}}$ receptor.

We proposed previously that neural crest-derived ectomesenchymal cells may be the major target of ET-1 in craniofacial development (10). In cardiovascular development, neural crest-derived ectomesenchymal cells which migrate from the pharyngeal arches to the outflow tract and walls of the arch arteries participate in outflow septation and formation of the great vessels (13-15). These ectomesenchymal cells provide support for the endothelium of the aortic arch arteries and form smooth muscle of the tunica media. Kirby and co-workers (22, 23) have shown that ablation of the neural crest results in outflow septation defects and aortic arch abnormalities similar to those of $E d n 1^{-1-}$ homozygotes in the chick embryo. Particularly, neural crest ablation causes disproportionate development of the third, fourth, and sixth arch arteries which form the proximal part of the great arteries, resulting in aortic arch malformations including aortic arch interruption. The developmental pattern of the arch arteries in $E d n 1^{-1-}$ homozygotes also represented similar inappropriate formation of the arch arteries and are consistent with disturbance in neural crest-derived cell lineage. In the process of aortic arch formation, interactions 

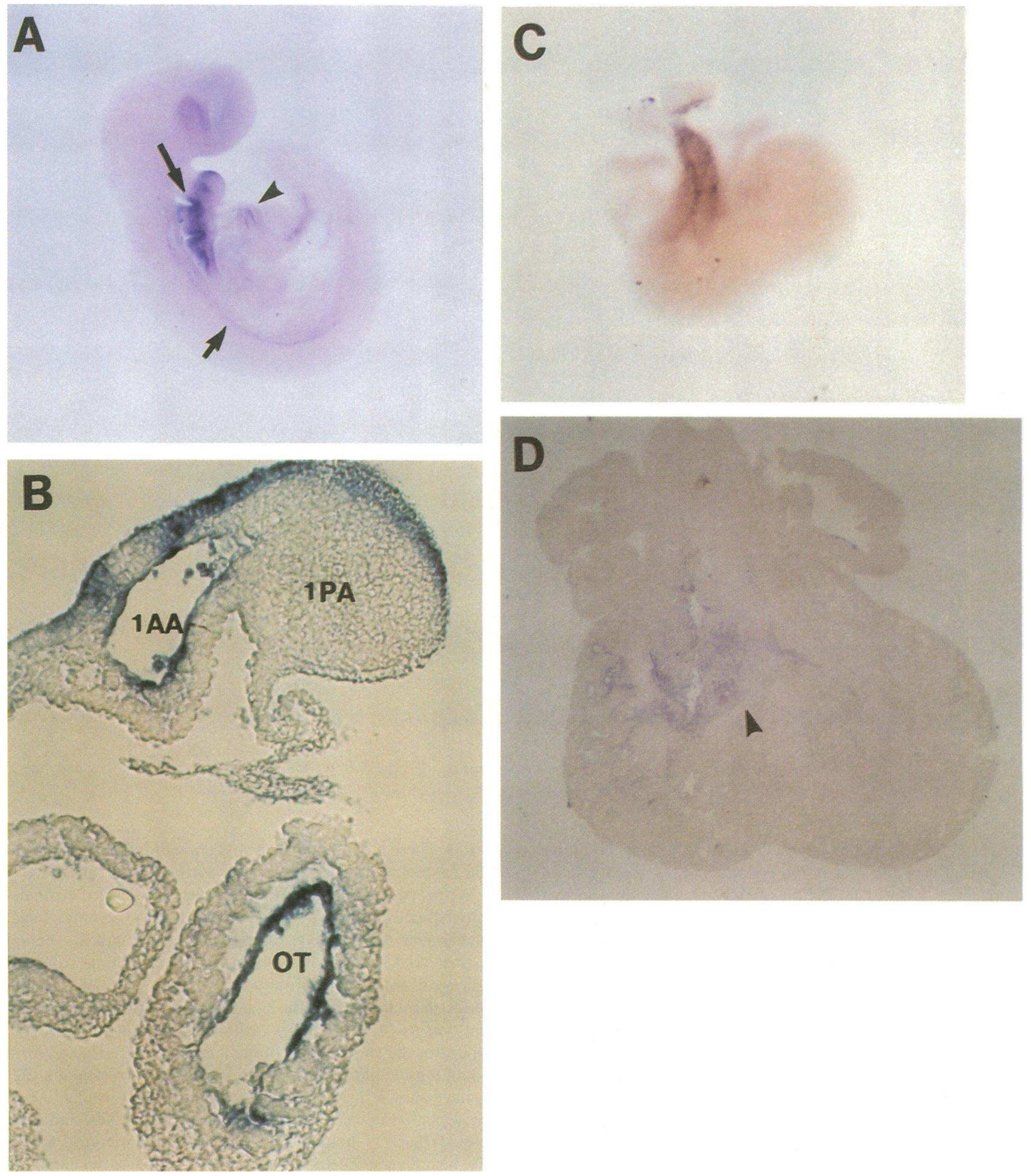

Figure 3. In situ hybridization of mouse embryos with the ET-1 probes (18). (A) Whole-mount hybridization of 10.0 d.p.c. embryo. The arrowhead indicates ET-1 signal in the outflow tract of the heart; the long arrow indicates ET-1 signal in the epithelium of the pharyngeal arches; the short arrow indicates ET-1 signal along the dorsal aorta. $(B)$ Paraffin section of $A$. ET-1 expression is detected in the endocardium of the outflow tract $(O T)$, the endothelium of the first pharyngeal arch artery $(I A A)$, and the epithelium of the first pharyngeal arch (IPA). (C) Whole-mount hybridization of the heart dissected from 11.5 d.p.c. embryo. High ET-1 expression is detected in the conotruncal region. $(D)$ Paraffin section of C. ET-1 expression is predominantly detected in the endocardial cushion (arrowhead). 
among all the elements of the pharyngeal arches including vascular endothelium, endoderm-derived epithelium of the pharyngeal pouch, ectoderm-derived epithelium of the pharyngeal grooves and arches, and neural crest-derived ectomesenchyme determine the fate of each arch artery $(13,14)$. In our study, phenotypic manifestations of $E d n 1^{-1-}$ homozygotes and high expression of ET-1 in the vascular endothelium and pharyngeal arch epithelium suggest that ET-1 may participate in these interactions as a factor from vascular endothelium and pharyngeal epithelium to determine arch artery development and that the cardiac neural crest cell lineage may be the major target of ET1 in cardiovascular development.

The genesis of ventricular septal defect is rather complicated. In the ventricular wall, the trabeculae condense at the interventricular groove give rise to the rudiment of the septum and grow inward, forming the major muscular portion of the septum (24). On the other hand, the endocardial cushion is formed by mesenchymal cells derived from endocardial cells migrating through a specialized extracellular matrix, cardiac jelly $(25,26)$. The endocardial cushion further expands to fuse with the muscular ventricular septum and aorticopulmonary septum, forming the membranous portion of the ventricular septum. Neural crest-derived cells have not been detected in this area and no direct evidence has been suggested that neural crest cells contribute to the formation of the ventricular septum (13). In experiments of neural crest ablation by Kirby and co-workers (22), however, ventricular septal defect was quite often associated with outflow tract malformations. Although this is attributed to the secondary effect of hemodynamic changes due to great vessel malformations, this fact and our present result give rise to the possibility that disturbance in neural crest cell lineage may directly affect the normal formation of the ventricular septum. It is also possible that ET-1 may directly contribute to the formation of the endocardial cushion and the proliferation of cardiomyocytes because ET-1 has a proliferative effect on a variety of mesenchymal cells and cardiomyocytes $(27,28)$. Especially, ET-1 is predominantly expressed in the endocardial cushion at 11.5 d.p.c., when the cushion is soon to form the membranous component of the interventricular septum. It requires further investigation to determine the target cells of ET1 effects in ventricular septal formation.

In situ hybridization demonstrates that ET-1 is highly expressed in the endocardium of the conotruncal region in comparison to that of the atrioventricular region. The conotruncal region forms differently than the other segments of the primary heart tube. This region is not yet present at the stage of fusion of the epimyocardial troughs; rather, it appears in subsequent stages of development (29). Correspondingly, conotruncal endocardial cells do not share common precursors with atrioventricular endocardial cells. Precursor cells from cephalic paraxial and lateral mesoderm migrate into the outflow tract to form the conotruncal endocardium, whereas precursor cells of the atrioventricular endocardium are derived from the cardiogenic plates (30). Differences in the pattern of ET-1 expression may be correlated to this developmental heterogeneity.

This study also indicates the existence of functional redundancy in the ET system in cardiovascular development. It cannot be definitely determined whether the functional redundancy of the role of ET-1 in cardiovascular development is caused by maternally derived circulating ET-1 or other ET isoforms (ET2 and/or ET-3). However, the following evidence argues against the latter possibility: (a) ET-2 is not detected in circulating blood and the plasma level of ET-3 is less than that of ET$1(31,32) ;(b)$ the affinity of ET-3 to ET $_{\mathrm{A}}$ receptor is about a thousand times as low as that of ET-1 and ET-2 (33); and (c) neither ET-2 nor ET-3 mRNA is detected in the heart of wildtype and homozygous mice (our unpublished data). Taken together, we are inclined to suppose that maternally derived ET1 could cause partial rescue of the cardiovascular phenotype of ET-1 null mutation. Recently, TGF- $\beta 1$ null mutation is reported to be rescued by maternal TGF- $\beta 1$ (34). The present result may be another example of maternal rescue of targeted gene disruption of secreted proteins.

In human diseases, ventricular septal defect and aortic arch anomalies including type B aortic arch interruption are shown to be associated with or a part of congenital syndromes including Pierre-Robin syndrome (35), DiGeorge syndrome $(36,37)$, and velo-cardio-facial syndrome (38), which involves craniofacial tissues and organs. Although many cases of these syndromes are closely linked to deletions in chromosome 22q11 (36-38), no causative genes are identified. The manifestations of these syndromes are quite similar to the phenotype of $E d n 1^{-/-}$homozygotes. Although the human ET-1 gene maps to chromosome 6 (39), this similarity of phenotype argues for a common developmental feature. In this context, the $E d n 1^{-1-}$ homozygous mice may be a useful model for these syndromes.

Recently, several genes have been suggested as contributors in cardiogenesis by transgenic approaches $(24,34,40-42)$. ET-1 may also participate in the molecular network in cardiovascular development. Thus, investigations on ET-1 in relation to other factors will give a clue as to the clarification of the mechanism of cardiovascular development and the pathogenesis of congenital heart diseases.

\section{Acknowledgments}

We thank H. Kato (Yamasa Shoyu Co. Ltd., Choshi, Japan) for monoclonal antibodies to ET-1; M. Isobe (Shinshu University, Matsumoto, Japan) for monoclonal antibodies to intercellular adhesion molecule; $Y$. Yamaguchi, M. Sasaki, C. Fujinami, and Y. Yamazaki for technical assistance; H. Suzuki, O. Ueda, and M. Miwa (CSK Research Park, Gotenba, Japan) for maintenance of mice; and R. M. Lawn (Stanford University, Stanford, CA) for critical reading of the manuscript.

Y. Kurihara is a Research Fellow of the Japan Society of the Promotion of Science. This work was supported by Grant-in-Aid for Scientific Research from the Ministry of Education, Science and Culture, Japan, the Mitsubishi Foundation, Uehara Memorial Foundation, and the Sankyo Foundation.

\section{References}

1. Yanagisawa, M., H. Kurihara, S. Kimura, Y. Tomobe, M. Kobayashi, Y. Mitsui, Y. Yazaki, K. Goto, and T. Masaki. 1988. A novel vasoconstrictor peptide produced by vascular endothelial cells. Nature (Lond.). 332:411-415.

2. Inoue, A., M. Yanagisawa, S. Kimura, Y. Kasuya, T. Miyauchi, K. Goto, and T. Masaki. 1989. The human endothelin family: three structurally and pharmacologically distinct isopeptides predicted by three separate genes. Proc. Natl. Acad. Sci. USA. 86:2863-2867.

3. Arai, H., S. Hori, I. Aramori, H. Ohkubo, and S. Nakanishi. 1990. Cloning and expression of a cDNA encoding an endothelin receptor. Nature (Lond.). 348:730-732.

4. Sakurai, T., M. Yanagisawa, Y. Takuwa, H. Miyazaki, S. Kimura, K. Goto, and T. Masaki. 1990. Cloning of cDNA encoding a nonisopeptide-selective subtype of the endothelin receptor. Nature (Lond.). 348:732-735.

5. Yanagisawa, M., and T. Masaki. 1989. Molecular biology and biochemistry of the endothelins. Trends. Pharmacol. Sci. 10:374-378. 
6. de Nucci, G., R. Thomas, P. D’Orleans-Juste, E. Antunes, C. Walder, T. D. Warner, and J. R. Vane. 1988. Pressor effects of circulating endothelin are limited by its removal in the pulmonary circulation and by the release of prostacyclin and endothelium-derived relaxing factor. Proc. Natl. Acad. Sci. USA. 85:97979800.

7. Masaki, T., S. Kimura, M. Yanagisawa, and K. Goto. 1991. Molecular and cellular mechanism of endothelin regulation. Implications for vascular function. Circulation. 84:1457-1468.

8. Luischer, T. F., C. M. Boulanger, Y. Dohi, and Z. H. Yang. 1992. Endothelium-derived contracting factors. Hypertension (Dallas). 19:117-130.

9. Vanhoutte, P. M. 1994. A matter of life and breath. Nature (Lond.). 368:693-694.

10. Kurihara, Y., H. Kurihara, H. Suzuki, T. Kodama, K. Maemura, R. Nagai, H. Oda, T. Kuwaki, W. H. Cao, N. Kamada, et al. 1994. Elevated blood pressure and craniofacial abnormalities in mice deficient in endothelin-1. Nature (Lond.) 368:703-710.

11. Noden, D. M. 1991. Cell movements and control of patterned tissue assembly during craniofacial development. J. Craniofacial Genet. Dev. Biol. 11:192-213.

12. Vainio, S., I. Karavanova, A. Jowett, and I. Thesleff. 1993. Identification of BMP-4 as a signal mediating secondary induction between epithelial and mesenchymal tissues during early tooth development. Cell. 75:45-58.

13. Kirby, N. L., and K. L. Waldo. 1990. Role of neural crest in congenital heart disease. Circulation. 82:332-340.

14. Kirby, M. L. 1993. Cellular and molecular contributions of the cardiac neural crest to cardiovascular development. Trends Cardiovasc. Med. 3:18-23.

15. Fishman, M. C., and D. Y. Steinier. 1994. Cardiovascular development Prospects for a genetic approach. Circ. Res. 74:757-763.

16. Hamaoki, M., H. Kato, M. Sugi, M. Fujimoto, H. Kurihara, M. Yoshizumi, M. Yanagisawa, S. Kimura, T. Masaki, and Y. Yazaki. 1990. Monoclonal antibodies to endothelin: application for sandwich immunoassays. Hybridoma. 9:63-69.

17. Ihara, M., K. Noguchi, T. Saeki, T. Fukuroda, S. Tuchida, S. Kimura, T. Fukami, K. Ishikawa, M. Nishikibe, and M. Yano. 1992. Biological profiles of highly potent novel endothelin antagonists selective for the $\mathrm{ET}_{\mathrm{A}}$ receptor. Life Sci. 50:247-255.

18. Miyauchi, T., R. Yorikane, S. Sasaki, T. Sakurai, M. Okada, M. Nishikibe, M. Yano, I. Yamaguchi, Y. Sugishita, and K. Goto. 1993. Contribution of endogenous endothelin-1 to the progression of cardiopulmonary alternations in rats with monocrotaline-induced pulmonary hypertension. Circ. Res. 73:887-897.

19. Anderson, R. H., A. E. Becker, and W. B. Robertson. 1993. Systemic Pathology. Volume 10. The Cardiovascular System. R. B. Robertson, editor. Churchill Livingstone, Edinburgh. 380 pp.

20. Wilkinson, D. 1992. Whole mount in situ hybridisation of vertebrate embryos. In In situ hybridisation: a practical approach. D. Wilkinson, editor. IRL, Oxford. 75-84.

21. Kaufman, M. H. 1992. The Atlas of Mouse Development. Academic Press, London. 131-133.

22. Nishibatake, M., M. L. Kirby, and L. H. Van Mierop. 1987. Pathogenesis of persistent truncus arteriosus and dextroposed aorta in the chick embryo after neural crest ablation. Circulation. 75:255-264.

23. Bockman, D. E., M. E. Redmond, K. Waldo, H. Davis, and M. L. Kirby. 1987. Effect of neural crest ablation on development of the heart and arch arteries in the chick. Am. J. Anat. 80:332-341.

24. Sucov, H. M., E. Dyson, C. L. Gumeringer, J. Price, K. R. Chien, and
R. M. Evans. 1994. RXR $\alpha$ mutant mice establish a genetic basis for vitamin A signaling in heart morphogenesis. Genes \& Dev. 8:1007-1018.

25. Kinsella, M. K., and T. P. Fitzharris. 1980. Origin of cushion tissue in the developing chick heart: cinematographic recordings of in situ formation. Science (Wash. DC). 207:1359-1360.

26. Fitzharris, T. P., and R. R. Markwald. 1982. Cellular migration through the cardiac jelly matrix: a stereoanalysis by high voltage electron microscopy. Dev. Biol. 92:315-329.

27. Takuwa, N., Y. Takuwa, M. Yanagisawa, K. Yamashita, and T. Masaki. 1989. A novel vasoactive peptide endothelin stimulates mitogenesis through inositol lipid turnover in swiss 3T3 fibroblasts. J. Biol. Chem. 264:7856-7861.

28. Ito, H., Y. Hirata, M. Hiroe, M. Tsujino, S. Adachi, T. Takamoto, M Nitta, K. Taniguchi, and F. Morumo. 1991. Endothelin-1 induces hypertrophy with enhanced expression of muscle-specific genes in cultured neonatal rat cardiomyocytes. Circ. Res. 69:209-215.

29. De la Cruz, M., C. Sánchez Gómez, M. M. Arteaga, and C. Argüello. 1977. Experimental study of the development of the truncus and the conus in the chick embryo. J. Anat. 123:661-686.

30. Noden, D. M. 1991. Origins and patterning of avian outflow tract endocardium. Development (Camb.). 111:867-876.

31. Suzuki, N., H. Matsumoto, C. Kitada, T. Masaki, and M. Fujino. 1989. A sensitive sandwich-enzyme immunoassay for human endothelin. J. Immunol. Methods. 118:245-250.

32. Matsumoto, H., N. Suzuki, H. Onoda, and M. Fujino. 1989. Abundance of endothelin-3 in rat intestine, pituitary gland and brain. Biochem. Biophys. Res. Commun. 164:74-80.

33. Masaki, T., J. R. Vane, and P. M. Vanhoutte. 1994. International union of pharmacology nomenclature of endothelin receptors. Pharmacol. Rev. 46:137142.

34. Letterio, J. J., A. G. Geiser, A. B. Kulkarni, N. S. Roche, M. B. Sporn, and A. B. Roberts. 1994. Maternal rescue of transforming growth factor- $\beta 1$ nul mice. Science (Wash. DC). 264:1936-1938.

35. Van Mierop, L. H., and L. M. Kutsche. 1986. Cardiovascular anomalies in DiGeorge syndrome and importance of neural crest as a possible pathogenetic factor. Am. J. Cardiol. 58:133-137.

36. Wilson, D. I., I. E. Cross, J. A. Goodship, S. Coulthard, A. H. Carey, P. J. Scambler, H. H. Bain, A S. Hunter, P. E Carter and J. Burn 1991. DiGeorge syndrome with isolated aortic coarctation and isolated ventricular septal defect in three sibs with a 22q11 deletion of maternal origin. Br. Heart. J. 66:308-312.

37. Wilson, D. I.,J. A. Goodship, J. Burn, I. E. Cross, and P. J. Scambler. 1992. Deletion within chromosome $22 \mathrm{q} 11$ in familial congenital heart disease. Lancet. 340:573-575.

38. Scamber, P. J., D. Kelly, E. Lindsay, R. Williamson, R. Goldberg, R. Shprintzen, D. I. Wilson, J. A. Goodship, I. E. Cross, and J. Burn. 1992. Velocardio-facial syndrome associated with chromosome 22 deletion encompassing the DiGeorge locus. Lancet. 339:1138-1139.

39. Bloch, K. D., S. P. Friendrich, M.-E. Lee, R. L. Eddy, T. B. Shows, and T. Quertermous. 1989. Structural organization and chromosomal assignment of the gene encoding endothelin. J. Biol. Chem. 264:10851-10857.

40. Chisaka, O., and M. R. Capecchi. 1991. Regionally restricted developmental defects resulting from targeted disruption of the mouse homeobox gene hox-1.5. Nature (Lond.). 350:473-479.

1. Jacks, T., T. S. Shin, E. M. Schmitt, R. T. Bronson, A. Bernards, and R. A. Weinberg. 1994. Tumour predisposition in mice heterozygous for a targeted mutation in $N f 1$. Nature Genet. 7:353-361.

42. Buckingham, M. 1994. Molecular biology of muscle development. Cell. $78: 15-21$. 